\title{
La ética de la Enfermería posmoderna
}

Nursing Ethics postmodern

Mtra.Teresa Sánchez Estrada.

Profesor de Carrera Asociado C, ENEO -UNAM.

La ética del cuidado enfermero en el contexto de la cultura moderna y posmoderna constituye un desafío teórico pero sobre todo práctico en las instituciones de salud. Según Francesc Torralba, siguiendo a E. Morín; hemos entrado al paradigma de la complejidad en la que no caben soluciones simples porque éstas, casi siempre son pragmáticas y muy frecuentemente carecen de anclaje valoral y axiológico. La tarea de cuidar al "otro" en situación vulnerable debe ser considerada en sí misma como un logro de la modernidad. El ejercicio de cuidar a un ser humano moderno es una actividad que exige la combinación de factores personales, profesionales , institucionales y sistémicos.

Cuidar en la modernidad supone un cambio de paradigma intelectual y práctico respecto al modelo vigente. Cuidar no quiere decir sobreproteger, ser paternalista encubierto o explícitamente. Cuidar de una persona implica cuidar de un sujeto único y singular en un contexto social determinado.
Por lo anterior el cuidado es un fenómeno que requiere un análisis multifactorial, no sólo humanista sino desde lo ético, estético, espiritua, y acompañado de los elementos antropológicos, sociológicos y políticos que lo justifican como una función social de primer orden.

En lo general, una vida ética incluye el equilibrio debidamente articulado entre el cuidado de sí, el cuidado del prójimo y el cuidado de la institución en la que se ofrecen los cuidados. Lo deseable es un ethos del cuidado pluralista que promueva el respeto a los demás aceptando que existen diferentes formas de expresión humanas a los que subyacen valores similares.

Sin embargo como afirma Torralba cuidar es difícil porque el ser humano es una "realidad poliédrica ambivalente y pluridimensional. Es un misterio, un ser inacabado y ambiguo por tanto la tarea de cuidar, asistir, ayudar para que sea "el mismo" es una tarea de magnitud insospechada. Cuidar es el gran reto del tercer milenio que requiere de competencia técnica, profesional y también exige un profundo conocimiento de las dimensiones psicológica, social, espiritual de la persona. En la libertad y la pluralidad se hace valer el estilo de vida admitiendo lo real. El respeto en la pluralidad acepta conductas diferentes pero valores comunes. El respeto permite la convivencia social. En la ideología de la pluralidad el respeto al otro es un principio indisputable.

Para Francesc Torralba el cuidar constituye el fundamento moral a partir del cual debe regirse la praxis profesional. "Cuidar requiere tiempo, espacio, dedicación, técnica, ciencia, sabiduría, conocimiento teórico y probada pericia enmarcados institucionalmente en una política social que haga posible cuidar a un ser humano, es decir, donde las condiciones estructurales sean favorables para el ejercicio profesional del cuidado"

El cuidado ético se expresa como una actitud y un estilo de ser 
y estar frente a los enfermos. Dicho estilo se sintetiza es un conjunto de cualidades manifestadas exteriormente, pero que provienen de la educación de los sentimientos y de una vida interior profunda lejana de las poses falsamente piadosas o afectadas. Cuidar no es una prestación o un favor realizado como si fuera un oficio, sino una manera de ser o un estilo de servir, una práctica ética. Dicha ética del cuidado es un atributo que hay que tener o esforzarse en adquirir como ser humano, pero especialmente si somos enfermeros. Para tener una actitud naturalmente buena y reconfortante hay que estar convencidos de que una sala de hospital es, en palabras de F. Colliere "un santuario del sufrimiento" y quienes ahí sufren esperan un cuidado ético, consciente y bien intencionado de quienes les cuidan.

Los actos humanos son éticos cuando son conscientes o abiertos a la conciencia. La conciencia ética tiene que ver con la llamada del otro, cercano o lejano, cualquier individuo que precisa de ayuda. El despertar de la conciencia ética tiene que ver con esta vocación de servir al otro. Un acto consciente implica saber y aceptar los alcances y consecuencias del mismo. Todo acto consciente adquiere un valor ético que va de bueno a malo con una gama sutil. Para valorar un acto se necesita conocer el acto, la finalidad y la circunstancia en la que tal acto se realiza.

Las circunstancias son determinantes para comprender la dimensión ética de una acción humana. Lo ético está siempre relacionado con lo bueno y verdadero. Lo bueno es aquello que es conforme la naturaleza, aquello que conduce o

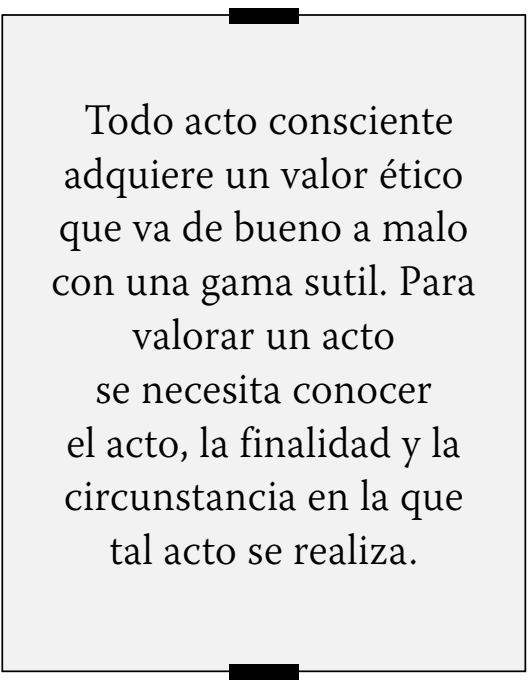

favorece al desarrollo humano, a la plenitud.

Para González Noriega la bioética es la ciencia que identifica valores y principios que orientan la conducta humana en el campo de las ciencias de la vida y de la salud. En enfermería hay que ubicar los valores que ayudan a ser mejores personas y mejores profesionistas en beneficio propio y de la persona cuidada.

Segun Noriega el ser humano está destinado a ser ético porque afortunadamente se nace sin "estar hecho". El ethos es algo a desarrollar dependerá de la cultura en la que se nace y a la que se pertenece. Es decir, el sujeto es ante todo un constructo social. El nacer sin estar hechos tiene como ventaja el ser libres, con la inteligencia y la voluntad para modelar una la personalidad y un estilo de vida. En la idea de González Noriega respecto del proceso de construcción de un ethos ético, reconoceremos que aunque los tiempos cambien los valores prevalecen. De esta manera destacamos los siete valores de la ética personalista como sustrato de una práctica, aplicables en tiempos modernos:
- Diligencia: para actuar con esmero asegurando que ningún daño se produzca o ningún bien deje de conseguirse a causa de la pasividad, descuido o pereza.

- Discreción: Reflejada en el secreto profesional y la interacción respetuosa con los colegas.

- Fiabilidad: en la que la confianza es el elemento sobre el que fluye la relación enfermera paciente.

- Fidelidad: con los compromisos y promesas, lealtad en el sentido de preocuparse de los intereses o situaciones delegadas para nuestro cuidado.

- Humildad: para aceptar que no todo se puede lograr. Que todo tiene un costo moral y por lo tanto un límite de acción y que todos corremos riesgo de equivocarnos.

- Prudencia: para considerar todas las posibles consecuencias de un acto o procedimiento que impliquen riesgos reales o potenciales para quien lo recibe.

\section{- Veracidad y honestidad:}

Porque la verdad es el principio de lo bueno

y lo bello.

Desde luego y coincidiendo con Torralba Roselló, el mínimo requisito para ser considerado ético es la responsabilidad frente al prójimo, la voluntad del bien, la responsabilidad frente al medio en la búsqueda de un consenso plural. La experiencia ética nace de la experiencia del otro. La experiencia de la alteridad, es la no indiferencia frente al otro $y$ 


\section{Enfermería Universitaria}

el sentido de responsabilidad frente a éste. Sólo puede hablarse de ética cuando el otro es respetado y atendido en su singularidad como acuerdo entre personas libres y responsables.

Coincidiendo con González Noriega un comportamiento ético es una evidencia del proceso de maduración psíquica de la persona y constituye la esencia para un comportamiento colectivo saludable. En particular la bioética es la plataforma en la que descansa el ethos del cuidado enfermero.

Dos conceptos fundamentales para F. Torralba son la compasión y la solicitud como plataforma del cuidado acompañada de la responsabilidad y la preocupación por el "otro" en toda relación profesional. Toda acción solicita tiene como génesis la "necesidad" del otro. Lo más lejano a la ética es el narcisimo o ensimismamiento moral, característicos de los tiempos modernos, en los que las personas y a veces los grupos, son incapaces de salir de sí mismos para abrirse al prójimo. Desde tal "encierro" difícilmente conocerán la experiencia ética.

Esto en la enfermería es muy importante porque implica que la enfermera defina responsablemente su propia posición ética con respecto al cuidado asegurando el respeto de la primacía de la persona humana traducida en el reconocimiento de su propia dignidad. La idea del ethos s personal no se o puede alcanzar solitariamente sino que requiere la apertura al prójimo dentro de instituciones justas. El lugar del desarrollo y el crecimiento de la persona se realizan dentro de las instituciones. La ética nos aclara que sólo es posible el cuidado de sí y el cuidado del prójimo si y sólo si; se cuidan también de las instituciones.

Un ethos ético personal e institucional supone trascender las posiciones individualistas o relativistas, en las que "todo se vale", y "cada quien atiene y atiende conforme a su verdad, creando su propia realidad”. Habrá que oír la advertencia de González Noriega para no dejar a la inteligencia abandonada en manos del capricho. Trabajemos diariamente para que la diligencia, la honestidad, la prudencia, la veracidad, la fiabilidad, la fidelidad, la discreción y sobre todo la humildad, filosóficamente entendidas definan el ethos enfermero Este es el reto de las nuevas instituciones para todas las generaciones. 